\title{
Social relationships and social support among post-war youth in Northern Uganda
}

\author{
Leen De Nutte ${ }^{1}$, James Okello², and Ilse Derluyn ${ }^{1}$ \\ ${ }^{1}$ Department of Social Work and Social Pedagogy \& Centre for Children in Vulnerable \\ Situations, Ghent University, Gent, Belgium \\ ${ }^{2}$ Department of Mental Health, Gulu University, Gulu, Uganda
}

\begin{abstract}
$A$ lthough social relationships and social support are salient factors for post-war adolescents' psychosocial coping and adjustment, there is only limited information regarding war-affected adolescents' views on social support and the relationships within which social support is provided. This study therefore explored both elements among a clinical sample of 20 adolescents living in post-war Northern Uganda. Following Braun and Clarke's thematic analysis, we found a prominent role of the biological mother and other primary biological family members in the upbringing of our participants. Spiritual and material support were perceived to be the most important type of support, respectively, while the adolescents were growing up and in their current lives. These findings provide support for the perception that caregiving systems are adaptable to particular sociocultural contexts. Further, the importance of particular functions of social support could signify a potentially selective buffering effect of these functions in adverse contexts. Because of the importance of the primary biological family and the salient role of parent-child relationships in the face of adversity, future research needs to focus on this particular kind of social relationship in contexts of prolonged collective violence.
\end{abstract}

Keywords: Social relationships; Social support; Post-war; Adolescent; Uganda.

An extensive body of research has focused on the importance of social relationships in the development and well-being of children and adolescents (McAuley \& Rose, 2014). One of the core constructs in social relationships is the social support which is given and received in the context of these relationships (Thompson, 2014). Many scholars have indicated the beneficial role of social support for people's well-being. As such, two major models have been suggested to explain this beneficial role: the main-effect model and the buffering model. The main-effect model posits that social support has a positive effect on well-being regardless of the presence of stress, while the buffering model suggests that social support can protect people from the potential harmful effects of stress (Cohen \& Syme, 1985). Regarding the buffering effect of social support in situations of prolonged collective violence, research has indicated the protective role of social support in children's coping with war-related events (Betancourt \& Khan, 2008). For example, in their longitudinal study of former child soldiers in Sierra Leone, Betancourt, Brennan, Rubin-Smith, Fitzmaurice, and Gilman (2010) found that social support was associated with higher levels of prosocial behaviours, especially in combination with community acceptance and school retention.

In Northern Uganda, however, studies exploring the beneficial role of social support have found differing results. A few studies have suggested that social support may be insignificant in buffering the effects of trauma on emotional well-being (Haroz, Murray, Bolton, Betancourt, \& Bass, 2013; Klasen et al., 2010). As such, Haroz et al. (2013) found that perceived social support did not significantly reduce depression and anxiety symptoms among a sample of displaced adolescents in Acholi sub-region. It has been suggested that these divergent findings on the role of social support in post-war settings may be due to the impact of collective violence on social relationships and networks (Vindevogel, Wessells, De Schryver, Broekaert, \& Derluyn, 2012). Individual and collective experiences resulting from living in situations

Correspondence should be addressed to Leen De Nutte, Department of Social Work and Social Pedagogy, Faculty of Psychology and Educational Sciences, Ghent University, Henri Dunantlaan 2, 9000 Ghent, Belgium. (E-mail: leen.denutte@ugent.be).

The authors would like to express their gratitude to all adolescents for participating in this research and Susan Ayot for providing support during the interviews. We hereby declare that all authors substantially contributed to the article with regard to the study's design (LDN, JO \& ID), data collection (LDN), data analysis and interpretation (LDN, JO \& ID), and article drafting and revision (LDN, JO \& ID). 
of prolonged collective violence put pressure on different levels of communities' social fabric (Derluyn, Vindevogel, \& De Haene, 2013). Further, it has been found that collective violence influences social relationships such as support structures, and family, caregiving and attachment relationships (Catani, 2010).

Derluyn et al. (2013) have emphasised the need for a relational understanding of the impact of collective violence on people's lives. Such an approach acknowledges interconnections between individual and collective meaning-making, and places notions of healing and suffering within the social context. Consequently, the emphasis has been on expanding research among war-affected populations, both during and in the aftermath of collective violence, and from an individual level to familial, social and communal levels (Catani, 2010; Derluyn et al., 2013).

However, social support has proven to be a complex concept to study given that it is a multifaceted construct (Cohen \& Syme, 1985). Despite several theoretical and empirical studies, the conceptualization of social support remains contentious as several definitions and measures of social support have been suggested (Cohen \& Syme, 1985). Furthermore, it is widely acknowledged that social support-as well as the relationships within which social support is given and received - is contextually embedded (Tuli, 2012). Given the multifaceted and contextually-determined nature of social support, several scholars have suggested that a distinction should be made between divergent types or functions of social support on the one hand and sources or providers of support on the other hand (Cohen \& Syme, 1985; Thompson, 2014).

Despite the important though variable role of social support in contexts of prolonged collective violence, there is only limited information regarding war-affected adolescents' views of social support and the relationships within which social support is provided (McAuley \& Rose, 2014). A better understanding and exploration of both elements could identify potential resources for youngsters facing adversity. This study therefore aimed at exploring the lived experiences of social relationships and social support as perceived by a clinical sample of adolescents living in post-war Northern Uganda. Two major research questions guided the study: (a) Which social relationships do the adolescents consider to be most important in their upbringing? and (b) What are the adolescents perceived functions and sources of social support?

To this end, we focused on an "extreme sample" of post-war adolescents with mental health problems, given that such samples can be particularly informative and enlightening (Patton, 2001). The rationale for selecting this sample was twofold. First, the social relationships and social support of adolescents who receive mental health care services - and thus are acknowledged as having mental health problems - imply an interesting ambiguity. Although social relationships and support could serve as potential resources in the amelioration of individuals' mental health problems (Umberson \& Montez, 2010), being diagnosed as having mental health problems might lead to negative social reactions, such as stigmatisation, exclusion and social rejection (Byrne, 2000). Second, adolescents are a remarkable group to include in this type of research given that adolescence is viewed as a period when peers take over important aspects of support provision from primary caregivers (Nickerson \& Nagle, 2005).

\section{METHOD}

The study was conducted in September-October 2012 in Gulu district, Northern Uganda. This area is currently in transition to peace after more than two decades of collective violence resulting from the conflict between the Lord's Resistance Army and the Ugandan government. The war had become known for its extreme cruelties against civilians, the mass abduction of children to act as child soldiers, and the forced displacement of the majority of the population by the government into Internally Displaced People's camps.

Criterion sampling (Patton, 2001) was used to select a convenience sample of adolescents who were receiving mental health services, at either the Gulu mental health unit or a school mental health programme. A maximum variation strategy (Patton, 2001) ensured the inclusion of adolescents who differed regarding sex and age.

Overall, 23 adolescents from Gulu district aged between 15 and 21 years were approached for in-depth interviews. Three adolescents declined to participate, with two saying they did not have time while one did not give reasons. Declining to participate in the interview did not interfere with the treatment the adolescents were receiving. This resulted in a total of 20 interviews involving 12 males and eight females (see Table 1).

A semi-structured interview with open-ended questions was administered to enable the participants to talk freely about their perceived social relationships and social support. All questions were designed by a bicultural research team of two Ugandans and two Belgians. First, sociodemographic characteristics were collected, after which open-ended questions were used to explore:

1 The most important social relationship figures in the upbringing of the adolescents. First, all important relationship figures were explored using an adaptation of Blaustein and Kinniburgh's (2010) "Circles of Trust" exercise (see Figure 1). This exercise was designed to visually support the participants in choosing significant others and placing them in order of importance during their upbringing (e.g., Why did you place your brother in the first circle? Why are the people you placed in the first circle more important to you than the people in the second circle?). Second, we elaborated on the 
TABLE 1

Socio-demographic characteristics of the participants

\begin{tabular}{ll}
\hline & Number of participants \\
\hline Gender & \\
Male & 12 \\
Female & 8 \\
Age & \\
$10-13$ & 2 \\
$14-16$ & 7 \\
$\geq 17$ & 11 \\
Schooling & \\
Primary school & 9 \\
Secondary school or secondary school drop-outs 11 \\
Tribe & \\
Acholi & 17 \\
Langi & 3 \\
Religion & \\
Catholic & 8 \\
Protestant & 6 \\
Born Again & 6 \\
Living situation & \\
With biological parent(s) & 10 \\
With relative & 5 \\
In boarding school & 5 \\
Number of people in the household (including participant) \\
1-4 & 6 \\
5-8 & 9 \\
$\geq 9$ & 5 \\
Marital status of parents & \\
Married or living together & 8 \\
Separated or divorced & 6 \\
One of the parents died or disappeared & 6 \\
\hline & \\
& \\
&
\end{tabular}

social relationship with the one person who was stated to be the most important figure during the participant's upbringing (e.g., Why did you choose your mother? How would you describe the relationship you have with your mother? How did your mother take care of you?).

2 The perception of functions and sources of social support. In order to explore the concept of social support in-depth, we combined open questions with specific questions related to the often-distinguished four types of social support (e.g., Cohen \& Syme, 1985): material (i.e., support through material and financial items), emotional (i.e., support for feelings), interpersonal (i.e., support for relationships with others) and spiritual (i.e., support in spirituality). Although we used this typology as an analytic framework, our data analysis started from an open perspective to ensure that we included all local and contextualised understandings that were presented during the interviews. Also, we explored the most important type of social support in the adolescents' upbringing and current life.

The interviews were conducted in either English or Luo (the local language) by an English-speaking researcher (LDN) and a trained bilingual translator. First, the purpose of the interview was explained to the

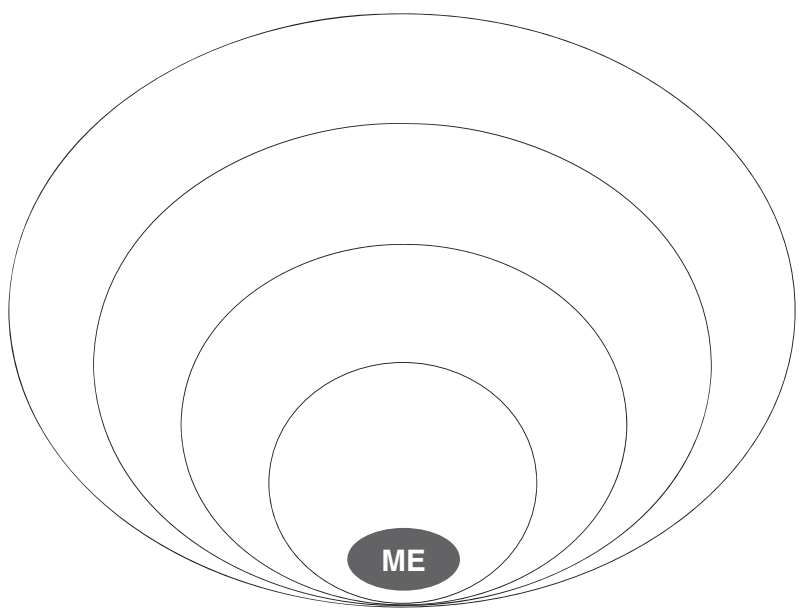

Figure 1. "Circles of Trust" exercise.

adolescents and their caregiver(s), and written informed consent and/or assent was obtained. Interviews took place in a setting that ensured privacy and confidentiality, either at the mental health unit $(n=15)$ or a primary boarding school $(n=5)$. Careful attention was given to verbal and non-verbal signs of distress during and after the interview. If required or observed, psychosocial support was provided by a skilled counsellor. All interviews were audiotaped and transcribed verbatim. The average time for completing the interviews was 55 minutes (range 43-146 minutes). Apart from refunding transport expenses, the participants received no compensation for their participation in this study.

The study was approved by the Ethical Committee of the Faculty of Psychology and Educational Sciences at Ghent University, the Faculty of Medicine at Gulu University, and the Uganda National Council for Science and Technology.

\section{Data analysis}

The Luo version of the in-depth interview records were translated into English and then analysed independently by the three authors (LDN, JO and ID). Following Braun and Clarke's (2006) thematic analysis method, a tree structure was developed after careful revision of the interview records and intensive discussions between the three coders. First, the research data were coded line-by-line. Patterns among these codes were abstracted, forming themes, and all coded data were sorted under these themes. After reviewing the content of the themes, against each other and against the original data set, they were labelled and reported using excerpts. More specifically, with regard to the first research question, Braun and Clarke's inductive thematic analysis was used to provide insights into the importance of particular social relationships. As we started from a pre-structured typology of 
social support to guide the analysis (see supra), Braun and Clarke's theoretical thematic analysis was used for the second research question on the meaning and importance of these support types. Additionally, as thematic analysis is a flexible method for doing qualitative analysis (Braun \& Clarke, 2006), we also used data-embedded quantifications in order to illustrate and further explore our qualitative data. To support data management during analysis, a software application for analysing qualitative data, NVIVO 9, was used.

\section{RESULTS}

\section{Important social relationships during upbringing}

Using an adaptation of Blaustein and Kinniburgh's (2010) "Circles of Trust" exercise, all social relationships in the participants' upbringing were explored. Primary biological family figures seemed to be most important for the majority of the adolescents, mainly their mother or father (see Figure 2). Extended family figures and peers, on the other hand, were mostly indicated in the periphery by the participants.

Braun and Clarke's (2006) inductive thematic analysis was used to elaborate themes regarding the importance of particular social relationships in the upbringing of the adolescents. The main reason for choosing the primary biological family as being the most important was because of the care the adolescents received from them. This care included nurturing, housework (e.g., cooking, washing clothes), taking responsibility for them and keeping track of them (e.g., at school). This theme also included the caregiver's ability to mobilise help from others whenever he/she was unable to provide the support alone without assistance, for example through obtaining money or a piece of land from the extended family.

Receiving guidance was also found to be a key aspect of the importance of the primary biological family figures. Our participants received advice and lessons, mainly on how to stay with and respect others. For example, one participant stated:

And time and again he tells me that "please, don't have anger on our parents. Leave our parents alone and you do your things." Because I was having a lot of anger towards my parents, but ... my elder brother kept on saying "let us do something good for our future and we leave our mother." (Male, 18 years)

The feeling of togetherness was also an important factor when referring to the primary biological family. Having dialogues with each other, sharing difficulties, being physically close to one another (e.g., living or working together) and being available seemed to comprise the core of this theme.
A fourth theme, being in a loving relationship, was another reason for choosing a primary biological family member as most important while growing up. This loving relationship included understanding the needs of the adolescent, showing love and being able to disclose problems and secrets.

Lastly, having a biological bond with primary biological family figures was also reported as a reason for being important in the adolescents' upbringing. This biological bond included some kind of obligation to provide support for the adolescent:

My sister is more important than my friend because there's that relationship which is linked from my mother and my father. My parents gave birth to us and we come from the same womb of my mother ... I have that authority to tell her [sister] to give me help. But if you go to a friend it is limited ... A friend may be reluctant because you're not from the same womb. (Male, 16 years)

Second, similar themes emerged as to why extended family figures were important for participants in the periphery: receiving care, receiving guidance and love and closeness. Concerning the care she received, one participant stated:

My aunt ... started staying with our grandmother ... and she got concerned about our situation. So she started supporting us frequent[ly], she started supporting us strongly.

(Female, 17 years)

Third, peers were less important to the adolescents while growing up because most of them were unable to provide material support. However, they could provide guidance to the adolescents. The adolescents also felt they were able to share their difficulties with their peers:

Sometimes they notice the difficulties I'm in, and if they ask me what difficulties I' $m$ in I always tell them especially our stay when I was in captivity. (Female, 14 years)

\section{Social relationship with the one most important caregiver}

Twelve of the adolescents indicated their biological mother as being the one most important person in their upbringing. Others reported their grandmother $(n=4)$, father $(n=3)$, or uncle $(n=1)$. The inductive thematic analysis revealed an interactional relationship between the adolescent and his/her one most important caregiver, including (a) themes directed from the adolescent to his/her caregiver; (b) themes in the interaction between them; and (c) themes directed from the caregiver to the adolescent (see Table 2).

Themes directed from the adolescent to the caregiver. All adolescents reported they took care of their caregivers 


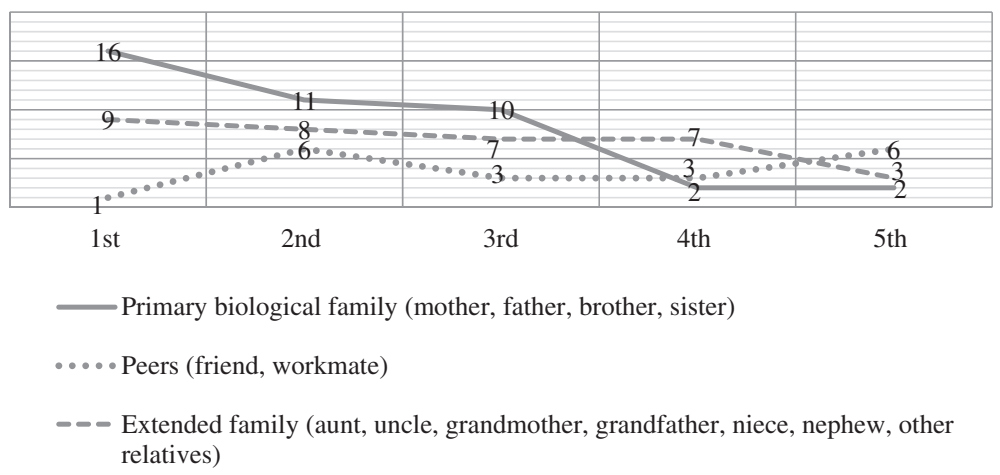

Figure 2. Important social relationships in the adolescents' upbringing by circle number. Circle one represents the relationships with figures who are most important; relationships placed in circle five are least important. The adolescents were allowed to include more than one figure in one circle.

TABLE 2

Key themes in the interactional relationship between the adolescents and their most important caregiver

\begin{tabular}{lll}
\hline $\begin{array}{l}\text { Adolescent to } \\
\text { caregiver }\end{array}$ & $\begin{array}{c}\text { Interaction } \\
\rightarrow\end{array}$ & $\begin{array}{c}\text { Caregiver to } \\
\text { adolescent }\end{array}$ \\
\hline - Supporting & $\leftarrow \rightarrow$ & $\leftarrow$ \\
- Respect and trust & - Togetherness & - Taking care \\
feelings & - Being equals & - Love and respect \\
& - Teaching and \\
& guidance
\end{tabular}

in diverse ways (providing care). Mainly, they did chores (e.g., washing clothes, fetching water). They could also provide their caregivers with material items, such as clothes, shoes or money they had earned. Many of our participants sympathised with their caregivers, for example, when there was little money. Lastly, the adolescents tried to make their caregivers feel good by impressing them with good school grades or thanking them for the good things they have done:

Sometimes if she's sick I carry her on the bicycle and take her to the hospital. And sometimes my grandmother could call me and asked me to... massage her ... This woman could not go to maybe in a community meetings and ... I carried her on the back of the bicycle. (Female, 18 years)

A second theme, respect and trust, included respecting the caregiver through immediately doing what he/she asked. The adolescents also trusted the caregiver not to do anything bad to them.

A final theme was having no negative feelings towards the caregiver, including not fearing, abusing or hating the caregiver. Instead, most adolescents spoke of their feelings of love towards their caregiver.

Themes in the interaction between the adolescent and his/her caregiver. A feeling of togetherness was the first theme in the interaction between the adolescents and their caregivers. This feeling was interpreted as physical closeness, for example, by living together, not being alone and missing the caregiver when he/she is not around.

Second, most adolescents addressed the need for good communication. Our participants felt they could share problems with their caregivers because they would listen attentively and tailor their messages to the level of the adolescent:

My grandmother communicated in a different way ... For my case, she can repeat something like four times. My brothers she can tell them like twice, maybe "you wash plates. I've told you to wash plates" ... But for my case she'll keep on repeating ... she keeps on telling me the same things in a politer way than those two children. (Female, 18 years)

Third, being equals was expressed through sharing a blood bond with the caregiver and behaving in a similar way.

Finally, several participants indicated that they perceived their relationship with their single most important caregiver as a parental relationship:

My grandmother took care of me like ... I'm her real child. Not like I'm a child to her daughter, not like I'm a child maybe to somebody else. But she took me like I'm a real child to her. (Female, 12 years)

Themes directed from the caregiver to the adolescent. Taking care of the adolescent was a key theme, mainly referring to the provision of different kinds of support. This support included material items (e.g., clothes), financial items (e.g., school fees), emotional support (e.g., disclosing problems), and taking the child to the hospital whenever needed:

I had skin rash and I almost lost ... both my hands and my legs. My mother was there but she couldn't take care of me and when my grandmother came in and picked me at that 


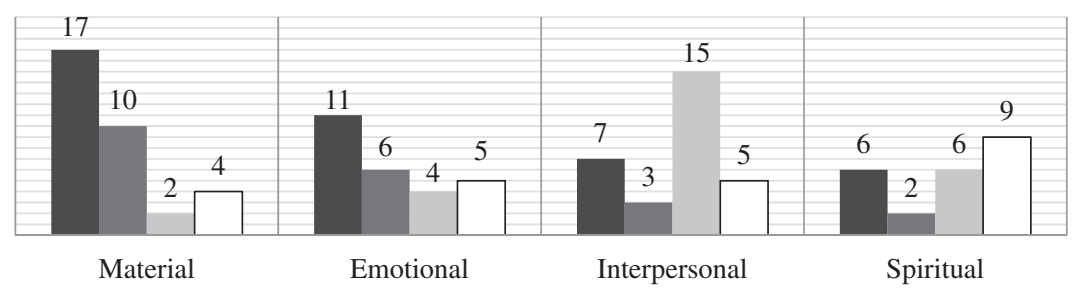

- Primary biological family (mother, father, brother, sister)

- Extended family (aunt, uncle, grandmother, grandfather, other relatives)

$\varpi$ Peers (friend, workmate, children of neighbours, classmate)

$\square$ Wider social support network (people from church, pastors, the Bible; neighbours,

LCs, community, village mates; teacher; NGO, nurses, health workers, radio)

Figure 3. Types and sources of social support. The adolescents were allowed to include more than one source of a particular kind of support.

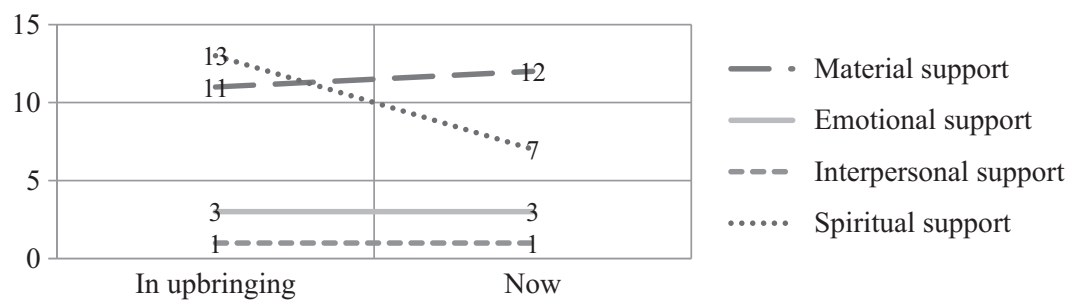

Figure 4. Most important type of support during the adolescents' upbringing and in their current lives. The participants were allowed to choose more than one kind of support.

tender age, she cared for me because she treated that hands of mine, took me to the hospital ... She continued taking care of me, she never returned me back to my mother. (Female, 18 years)

Several participants felt they received enough care from their caregivers, despite the latter not always being able to meet all of their (basic) needs.

A second theme, love and respect, included understanding and knowing the needs and problems of the adolescent, accepting the adolescent the way he/she is, and feelings of love. One participant addressed the way her mother protected her when escaping from LRA captivity:

On the way when we were escaping ... we came across some soldiers and we got a women who had just given birth to a very small child ... So that child was given to me to kill ... but my mother came up. She came up and told the rebels that "please, maybe you let me to kill this baby." So the baby was given to my mother so that my mother killed [it] ... If you to see that relationship, my mother was there, she had sacrificed herself because her coming out to tell the rebels that "I'm going to kill this child" was enough to actually do away with my mother's life. But she didn't see that, she was only seeing me. So she really surrendered a very high protection over me and she killed the baby. (Female, 14 years)
Lastly, the majority of our participants indicated the teaching and guidance they received from their caregivers, such as the advice they had received on how to live with other people (e.g., the importance of forgiveness).

\section{Functions and sources of social support}

Braun and Clarke's (2006) theoretical thematic analysis was used to elaborate themes regarding the meaning of the different types of social support (material, emotional, interpersonal and spiritual) in the adolescents' upbringing and current life. Further, the participants were asked to indicate which support figures provided these types of support (see Figure 3).

Fees for education were the most important material support. Other forms of material support included basic needs such as medical care, shelter, food and clothing. Disclosure was the most important aspect of emotional support, including exchanging with others (e.g., problems, ideas), receiving from others (e.g., counselling, solutions to problems, hope, love) and giving to others (e.g., forgiveness). In contrast, some adolescents mentioned they did not share their concerns with others. Interpersonal support included physically being together and, more specifically, doing things together (e.g., school work or playing). Regarding spiritual support, receiving 
guidance and advice from spiritual figures and communicating with God through prayer were most commonly mentioned.

The primary biological family appeared to be the most important source of material and emotional support. Peers were the most common provider of interpersonal support. The wider social support network, including community, school, church and service figures, was the most often reported source of spiritual support.

\section{Most important type of social support}

The most important kind of support received during the adolescents' upbringing was spiritual support (see Figure 4). Praying alone or in a group gave the participants relief and supported them when they were feeling down or were having mental problems:

With my condition I get a lot of challenges. When I move people look at me ... When I go to church, I get a lot of bible reading and always in the bible they've said "we people are the image of God." Then it makes me sometimes happy [to] say "why did God created me in this way? Maybe I'm special," but if not, if I'm start thinking like a human being without God, by now I would have even committed suicide. And I forget that ... I'm not a human being just but I'm also special by God. It is God who created me. (Female, 15 years)

With regard to current support needs, material support was the most important for the adolescents, especially their need for education and material items (e.g., food, clothes).

\section{DISCUSSION}

This study qualitatively explored the social relationships and social support among a clinical sample of adolescents living in post-war Northern Uganda. Our findings reveal a prominent role for the primary biological family in the upbringing of the adolescents, particularly the biological mother. The adolescents' relationship with their single most important caregiver appeared to be interactional, with support given and received by both relational partners. Our participants further reported a dominant role for spiritual support in their upbringing, and material support in their current lives. Only a limited role was found for emotional and interpersonal support.

The primary biological family appeared to be most important to our participants while growing up. More specifically, this study indicated a key role of the biological mother, which might relate to a more universal feature of caregiving systems. In most societies around the world mothers take on most of the caregiving responsibilities (Wood \& Eagly, 2002). Belle and Benenson (2014) argue that mothers are considered to be of paramount importance because of the support they themselves provide and their role in facilitating other relationships and support for their children. However, this prevailing importance of the nuclear family seems to be in contrast with the idea that the extended family takes on an important role in the caregiving system in, for example, sub-Saharan Africa (Mathambo \& Gibbs, 2009). In this regard, Keller (2002) proposes that, starting from a universal caregiving repertoire, caregiving is adaptable to the particular sociocultural context. Hence, local conceptions of caregiving can be developed which may differ between and within groups. Our finding that the nuclear family seemed to be of key importance in the upbringing of our participants could be an example of a local conception of caregiving relationships. This result could thus indicate an intra-group difference regarding this common idea about the importance of the extended family in "collective" households. It is plausible that the caregiving system of our participants got adapted to the prolonged collective violence in Northern Uganda (Catani, 2010; Derluyn et al., 2013). Alternatively, modernization and the consequent shift from communal to individual responsibilities for child-rearing and support provision could have resulted in the extended family no longer feeling entitled to provide support to the wider family system (Bamurange, 2004). Similar explanations can be used to explain the potential inter-group difference regarding the finding that there is a shift in support provision during adolescence from primary caregivers to peers (Nickerson \& Nagle, 2005). Illustrative of this is that our participants considered the single important person while growing up to be someone able to provide care. Consequently, peers were perceived to be less important because they were unable to provide this care.

The interactional relationship between the adolescents and their caregivers included aspects of support given and received by both relational partners. This finding is consistent with the idea of transactional relationships in which adolescents are perceived as "agents of socialization," instead of passive recipients in their own upbringing (Thompson, 2014). In this regard, we follow Geens and Vandenbroeck (2012) in perceiving social support as a construct which exists within the relationship between the person giving and the person receiving support, rather than as an individual quality.

Fees for education were the most important components of material support. The breakdown of educational structures as a result of collective violence, with a consequential loss of educational opportunities (Dupuy \& Peters, 2010), might be plausible reasons as to why many people in Northern Uganda attach high significance to education. Material support was chiefly provided by the primary family and was perceived to be the most important kind of support in the current lives of our participants. Further, disclosure of problems, ideas and stories were the 
predominant aspects of emotional support. Again, the primary biological family was most important in providing this type of support. The most important aspect of interpersonal support involved being or doing things together and was prominently provided by peers. Although the salience of emotional and interpersonal support has been reported in previous research on war-affected adolescents (Betancourt \& Khan, 2008; Vindevogel et al., 2012), our participants only indicated a limited role for these types of support. The tendency to report direct needs (i.e., material and spiritual support) may have led to an underestimation of other kinds of support (Vindevogel et al., 2012). Emotional and interpersonal support might thus signify a valuable contribution in a less visible, non-tangible manner or in the longer term. Alternatively, the key role of material and spiritual support could signify that these particular functions might contribute divergently to the protective role of social support in this particular context or among this specific population. It might thus be fruitful for further research to differentiate between types (and sources) of social support, instead of applying a general measure. Such an approach could provide us with more nuanced results, and reflects the need for context-sensitive research on social support (Tuli, 2012). Further, receiving guidance from spiritual figures and communicating with God seemed to comprise the core of spiritual support. This support was mostly provided by the wider social support network, including community, school, church and service figures. This type of support was also most important while the adolescents were growing up. The role of spiritual support has previously been documented as a key coping mechanism when faced with adversity (Klasen et al., 2010).

\section{Limitations}

The study was based on adolescents' accounts and therefore subject to potentially biased reporting. The respondents may not have described their experiences in full, for two reasons. First, some of the adolescents were interviewed just before discharge and may therefore have had difficulty describing their relationships, especially if this had influenced symptoms or precipitated their seeking treatment. Second, the participants may not have wished to be reminded of the negative relational circumstances that may have led to their mental health symptoms, and may therefore have evaded answering questions that were emotionally challenging. Although a saturation effect was achieved, the small sample of 20 consecutively selected adolescents limits the generalizability of the study's results. Community-based adolescents who were not specifically seeking mental health care were not included in the study. The selection of the adolescents was purposive and therefore we relied on a convenience sample, as a completely randomised selection was not possible because of the intensive cooperation required from the families. Nevertheless, the strength of the study was that we included measures to differentiate between relationships with and support from various figures in the upbringing of the participants.

\section{Implications}

The use of a network perspective to explore social relationships with important caregiving figures clearly helps the potential identification of unexplored sources which can be engaged in finding suitable support for the adolescent and his/her environment (Blaustein \& Kinniburgh, 2010). In this regard, it has been suggested that interventions for adolescents are more effective if directed at the broader systemic context rather than focused solely on the individual (Derluyn et al., 2013).

Through the exploration of perceived social support, we gained some insight into our participants' current support needs. Education seems to be most important for our participants nowadays. Although restoring educational structures and providing educational opportunities has been stressed as an important contributor towards post-war reconstruction, ensuring education for all remains an important challenge in many (post-)war settings (Dupuy \& Peters, 2010).

This research further underscores the need to study social relationships and support in their particular context (Tuli, 2012), whereby inter- and intra-group differences in caregiving systems are acknowledged (Keller, 2002). Hence, contextual sensitivity in the planning, execution and evaluation of interventions is key and more research is needed regarding social relationships and support in divergent contexts.

Finally, the primary biological family appeared to be the principal caregiving system for the majority of the adolescents. A closer exploration of the parent-child relationship in particular and parenting in general might be an interesting topic for further research. However, research on how prolonged collective violence might impact on parenting is lacking (Catani, 2010). In this regard, we stress studying parenting-in-context, since parenting should be regarded as a shared responsibility between divergent actors (Geens \& Vandenbroeck, 2012). It might thus be fruitful to apply a functional definition of "parents" that includes all persons who can provide for children and youngsters what they need, instead of a structural definition of who is supposed to provide, namely the biological parents (Ager, 2006).

Manuscript received November 2014 Revised manuscript accepted August 2015

\section{REFERENCES}

Ager, A. (2006). What is family? The nature and functions of families in times of conflict. In N. Boothby, A. Strang, 
\& M. Wessells (Eds.), A world turned upside down: Social ecological approaches to children in war zones (pp. 39-62). Bloomfield, CT: Kumarian Press.

Bamurange, V. (2004). The dilemma of parenting. In M. K. Rwebangira \& R. Liljeström (Eds.), Umleavyo: The dilemma of parenting (pp. 8-22). Spain: Grafilur Artes Grafícas.

Belle, D., \& Benenson, J. (2014). Children's social networks and well-being. In A. Ben-Arieh, F. Casas, I. Frønes, \& J. E. Korbin (Eds.), Handbook of child well-being: Theories, methods and policies in global perspective (pp. 1335-1363). Dordrecht, NL: Springer.

Betancourt, T. S., \& Khan, K. T. (2008). The mental health of children affected by armed conflict: Protective processes and pathways to resilience. International Review of Psychiatry, 20, 317-328. doi:10.1080/09540260802090363.

Betancourt, T. S., Brennan, R. T., Rubin-Smith, J., Fitzmaurice, G. M., \& Gilman, S. E. (2010). Sierra Leone's former child soldiers: A longitudinal study of risk, protective factors, and mental health. Journal of the American Academy of Child \& Adolescent Psychiatry, 49, 606-615. doi:10.1016/j.jaac.2010.03.008.

Blaustein, M. E., \& Kinniburgh, K. M. (2010). Treating traumatic stress in children and adolescents: How to foster resilience through attachment, self-regulation, and competency. New York, NY: Guilford Press.

Braun, V., \& Clarke, V. (2006). Using thematic analysis in psychology. Qualitative Research in Psychology, 20, 77-101. doi:10.1191/1478088706qp063oa.

Byrne, P. (2000). Stigma of mental illness and ways of diminishing it. Advances in Psychiatric Treatment, 6, 65-72. doi:10.1192/apt.6.1.65.

Catani, C. (2010). War at home: A review of the relationship between war trauma and family violence. Verhaltenstherapie, 20, 19-27. doi:10.1159/000261994.

Cohen, S., \& Syme, S. L. (1985). Issues in the study and application of social support. In S. Cohen \& S. L. Syme (Eds.), Social support and health (pp. 3-22). San Francisco, CA: Academic Press.

Derluyn, I., Vindevogel, S., \& De Haene, L. (2013). Toward a relational understanding of the reintegration and rehabilitation processes of former child soldiers. Journal of Aggression, Maltreatment \& Trauma, 22, 869-886. doi:10.1080/10926771.2013.824058.

Dupuy, K. E., \& Peters, E. (2010). War and children: A reference handbook. Westport, MI: Greenwood Press.

Geens, N., \& Vandenbroeck, M. (2012). The (ab)sense of a concept of social support in parenting research: A social work perspective. Child \& Family Social Work, 19, 491-500. doi:10.1111/cfs.12048.
Haroz, E. E., Murray, L. K., Bolton, P., Betancourt, T. S., \& Bass, J. K. (2013). Adolescent resilience in Northern Uganda: The role of social support and prosocial behavior in reducing mental health problems. Journal of Research on Adolescence, 23(1), 138-148. doi:10.1111/j.1532-7795.2012. 00802.x.

Keller, H. (2002). Development as the interface between biology and culture: A conceptualisation of early ontogenetic experiences. In H. Keller, Y. H. Poortinga, \& A. Schölmerich (Eds.), Between culture and biology: Perspectives on ontogenetic development (pp. 215-240). Cambridge, U.K.: Cambridge University Press.

Klasen, F., Oettingen, G., Daniels, J., Post, M., Hoyer, C., \& Adam, H. (2010). Posttraumatic resilience in former Ugandan child soldiers. Child Development, 81, 1096-1113.

Mathambo, V., \& Gibbs, A. (2009). Extended family childcare arrangements in a context of AIDS: Collapse or adaptation? AIDS Care, 21, 22-27. doi:10.1080/09540120902942949.

McAuley, C., \& Rose, W. (2014). Children's social and emotional relationships and well-being: From the perspective of the child. In A. Ben-Arieh, F. Casas, I. Frønes, \& J. E. Korbin (Eds.), Handbook of child well-being: Theories, methods and policies in global perspective (pp. 1917-1954). Dordrecht, NL: Springer.

Nickerson, A. B., \& Nagle, R. J. (2005). Parent and peer attachment in late childhood and early adolescence. Journal of Early Adolescence, 25, 223-249. doi:10.1177/0272431604274174.

Patton, M. Q. (2001). Qualitative research and evaluation methods (2nd ed.). Thousand Oaks, CA: Sage.

Thompson, R. A. (2014). Why are relationships important to children's well-being?. In A. Ben-Arieh, F. Casas, I. Frønes, \& J. E. Korbin (Eds.), Handbook of child well-being: Theories, methods and policies in global perspective (pp. 1917-1954). Dordrecht, NL: Springer.

Tuli, M. (2012). Beliefs on parenting and childhood in India. Journal of Comparative Family Studies, 43(1), 81-91. doi:10.3325/cmj.2011.52.637.

Umberson, D., \& Montez, J. K. (2010). Social relationships and health: A flashpoint for health policy. Journal of Health \& Social Behavior, 51, S54-S66. doi:10.1177/0022146510383501.

Vindevogel, S., Wessells, M., De Schryver, M., Broekaert, E., \& Derluyn, I. (2012). Informal and formal supports for former child soldiers in Northern Uganda. The Scientific World Journal, 2012, 10. doi:10.1100/2012/825028.

Wood, W., \& Eagly, A. H. (2002). A cross-cultural analysis of the behaviour of women and men: Implications for the origins of sex differences. Psychological Bulletin, 128(5), 699-727. doi:10.1037//0033-2909.128.5.699. 